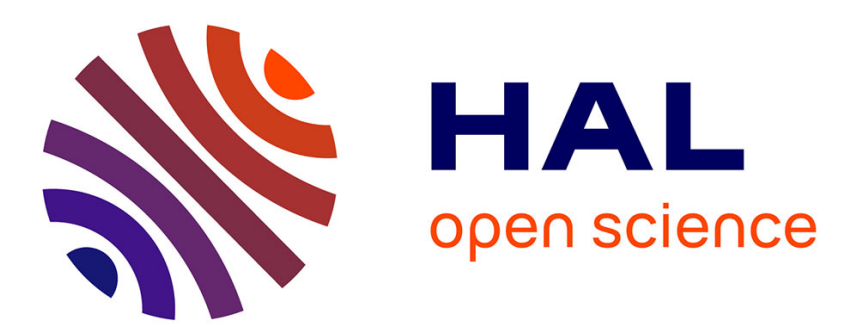

\title{
DC-DC converter with GaN transistor and coupled with monolithic ICT sintered by PECS/SPS
}

Adrien Mercier, Fabien Adam, Denis Labrousse, Bertrand Revol, Oleksandr

Pasko, Frédéric Mazaleyrat

\section{> To cite this version:}

Adrien Mercier, Fabien Adam, Denis Labrousse, Bertrand Revol, Oleksandr Pasko, et al.. DC-DC converter with GaN transistor and coupled with monolithic ICT sintered by PECS/SPS. EPE Journal - European Power Electronics and Drives, 2019, 10.1080/09398368.2019.1585707 . hal-02401703

\section{HAL Id: hal-02401703 \\ https://hal.science/hal-02401703}

Submitted on 10 Dec 2019

HAL is a multi-disciplinary open access archive for the deposit and dissemination of scientific research documents, whether they are published or not. The documents may come from teaching and research institutions in France or abroad, or from public or private research centers.
L'archive ouverte pluridisciplinaire HAL, est destinée au dépôt et à la diffusion de documents scientifiques de niveau recherche, publiés ou non, émanant des établissements d'enseignement et de recherche français ou étrangers, des laboratoires publics ou privés. 


\title{
DC-DC converter with GaN transistor and coupled with monolithic ICT sintered by PECS/SPS
}

\author{
Adrien Mercier ${ }^{1}$, Fabien Adam ${ }^{1}$, Denis Labrousse ${ }^{2}$, Bertrand Revol $^{1}$, Alexandre Pasko ${ }^{1}$, Frédéric Mazaleyrat ${ }^{1}$ \\ ${ }^{1}$ SATIE, ENS Paris-Saclay, CNRS, Universite Paris-Saclay, 61 avenue Président Wilson, 94230 Cachan, France \\ ${ }^{2}$ SATIE, CNAM, 292 rue Saint-Martin, 75003 Paris, France
}

\begin{abstract}
This paper presents an implementation of the voltage regulator module (VRM) DC-DC converter operating at $2 \mathrm{MHz}$ using 3 interleaved switching cells whose outputs are magnetically coupled by monolithic intercell transformers (ICT). The innovation comes from the manufacturing of the ICTs. Spinel ferrite is sintered around two copper windings by pulsed electric current sintering (PECS), also called spark plasma sintering (SPS). The manufacturing processes are detailed in this paper, and the ICTs magnetic properties are measured. The high-frequency operation of the converter has been possible thanks to the implementation of GaN components. The power density of the converter is $15 \mathrm{~kW} / \mathrm{dm}^{3}$.
\end{abstract}

Keywords: PECS or SPS, ICT, interleaved VRM converter, power integration

\section{INTRODUCTION}

Since the advent of power electronics, some of the technology issues were orchestrated around increasing power densities and now are focusing on integration. The main determining factor is to always increase the active components operating frequency in order to reduce size and mass of passive components while thermal constraints are respected. Nowadays, one can find converters using wide band gap components like $\mathrm{GaN}$ transistors that have the advantage of a very low switching times, thus reducing the switching losses and allowing a high switching frequency operation within the megahertz band. Moreover, new technologies allow to glimpse a new approach for the design of passive components [1].

In this study a static DC-DC converter is developed based on the voltage regulator module (VRM) structure with three interleaved and coupled phases. This converter has three switching cells whose outputs are magnetically coupled using couplers or intercell transformers (ICT) as a cyclic arrangement [2][3][4]. The schematic diagram is shown in Figure 1.

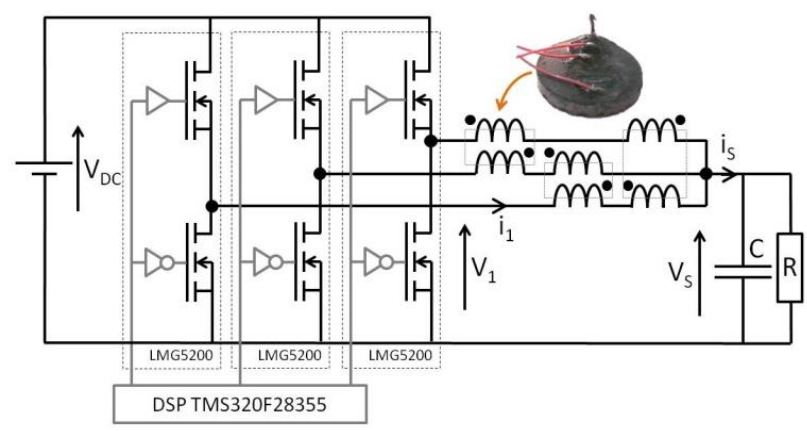

Figure 1. Scheme of an interleaved coupled VRM converter.
The originality of this study consists in that the monolithic ICTs have been made by pulsed electric current sintering (PECS), also known as spark plasma sintering (SPS). This sintering technology allows to manufacture a wide variety of materials, such as metals, glasses, or ceramics [5][6][7]. The protocol to sinter $\mathrm{MnZn}$ ferrite or NiCuZn ferrite was clearly described in [8], and improve in order to obtain dense ferrite in [9]. The fabrication of monolithic magnetic components was firstly proposed in [10] and a prototype is produced in [11]. Self and mutual inductances of these couplers have constant values in the frequency band from $10 \mathrm{kHz}$ to $10 \mathrm{MHz}$. Therefore, the switching cells based on Texas Instruments GaN components (LMG5200) operating at a switching frequency of $2 \mathrm{MHz}$ have been implemented.

Firstly, the manufacturing process and the electrical characteristics of the couplers are presented. Secondly, simulation results of the integrated device are shown. Finally, some details about the prototype construction and performance are provided.

\section{MANUFACTURING PROCESS AND THE ELECTRICAL CHARACTERISTICS OF ICTS}

ICTs are monolithically implemented using PECS/SPS. These magnetic components are very efficient for heat dissipation. Exploded and cross-section views are shown in Figures 2 and 3 to illustrate the topology and operation of the components.

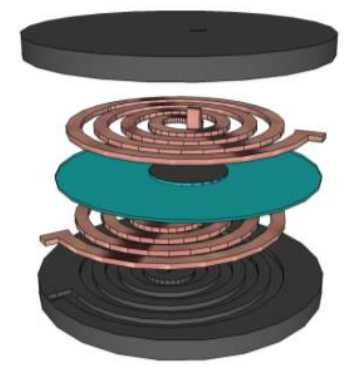

Figure 2. Exploded view of a monolithic coupler (ICT).

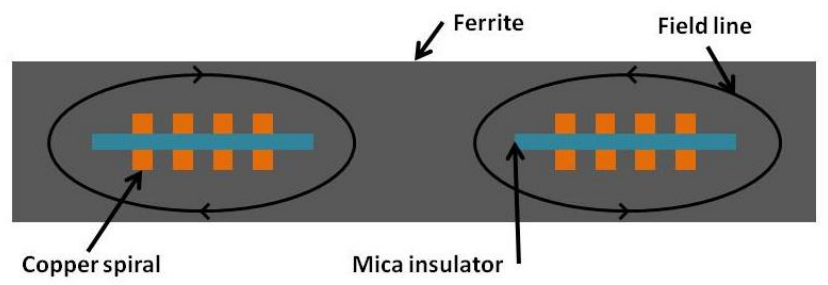

Figure 3. Sectional view of monolithic coupler (ICT). 
Firstly, spinel ferrite powder with the following chemical formula $\mathrm{Ni}_{0.27} \mathrm{Zn}_{0.57} \mathrm{Cu}_{0.16} \mathrm{Fe}_{2} \mathrm{O}_{4}$ has been chosen. $\mathrm{NiZnCu}$ ferrites are known for their range of permeability [12], and especially for their low sintering temperature [13][14]. In order to improve the sintering, the size of the particles is reduced by grinding, which increases the reactivity of the powder. The grinding at $450 \mathrm{rpm}$ for 3 hours was carried out in a Fritsch Pulverisette 6 planetary mill. A grinding bowl of $45 \mathrm{~cm}^{3}$ was used, in which $5.5 \mathrm{~g}$ of powder and 18 chrome-plated steel balls of diameter $7 \mathrm{~mm}$ and mass $1.4 \mathrm{~g}$ were placed. Then 55 $\mathrm{mg}$ of $\mathrm{V}_{2} \mathrm{O}_{5}$ was added, corresponding to $1 \%$ of the mass of ferrite powder. Vanadium pentoxide has a melting point of 680 ${ }^{\circ} \mathrm{C}$ and plays the role of a flux which allows the transition from solid phase sintering to liquid phase sintering [15][16]. This improves the mobility of the ions during sintering, thus leading to a density close to the theoretical one.

Secondly, copper spirals as coils were used. They had been fabricated by electrical discharge machining (EDM) from a $0.45 \mathrm{~mm}$ thick copper plate. The cutting machine is the Robofil 300 model from Charmilles Technologies. Each spiral is made up of 4 turns. The width of the spiral is $0.5 \mathrm{~mm}$, and the distance between each turn is also $0.5 \mathrm{~mm}$. Two shapes have been created, corresponding to the two windings (upper and lower) of the ICTs, as shown in Figure 4.

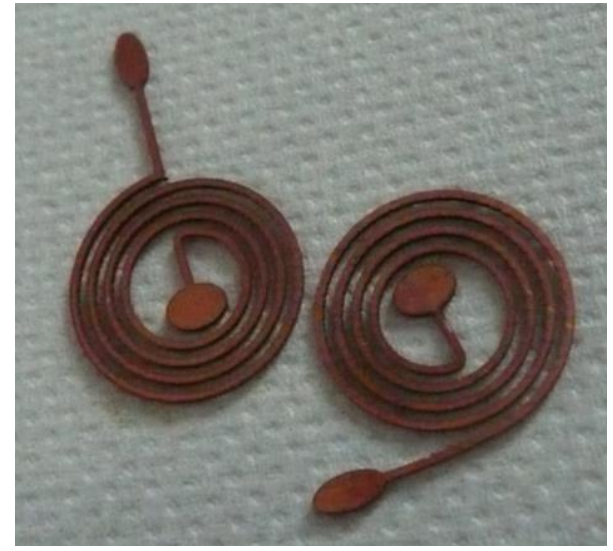

Figure 4. Copper spirals machined by EDM.

Thirdly, a mica washer insulator was inserted between the two spirals as illustrated in Figure 2. The mica washer thickness is $0.4 \mathrm{~mm}$. Then, the ends of the spirals were bent upwards and the copper was isolated from the ferrite using alumina charged paint as shown in Figure 5. Indeed, the PECS/SPS process is reducing, in the sense that the concentration of $\mathrm{O}^{2-}$ ions in the ferrite is reduced [17]. Consequently, an electronic reorganization takes place, and $\mathrm{Fe}^{2+}$ ions appear which reduce the resistivity of the ferrite. The resistivity of ferrite sintered by PECS/SPS is about $50 \Omega . \mathrm{m}$, whereas in a conventionally sintered $\mathrm{Ni}-\mathrm{Zn}$ ferrite it can reach $10^{8} \Omega . \mathrm{m}$.

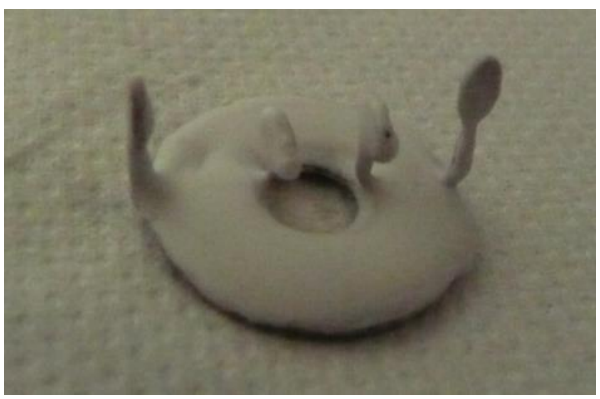

Figure 5. Spirals and washer covered with ceramic paint.
Afterwards, all the various materials were assembled in the sintering die. This die consists of a graphite tube with an internal diameter of $20 \mathrm{~mm}$ and two graphite pistons. Since the nature of this material favours the reduction of ferrite, two production strategies are presented below. The size of this internal diameter constrained the size of the ICTs.

\subsection{First ICT production method.}

For the first trial, 2 grams of powder were placed in the graphite die, followed by the spiral-washer-painting set and 2 more grams of powder. In order to protect the ends of the spirals from the uniaxial pressure applied during sintering, they were buried under alumina powder which has a sintering temperature much higher than that of ferrite. A section of the filled die before sintering is shown in Figure 6.

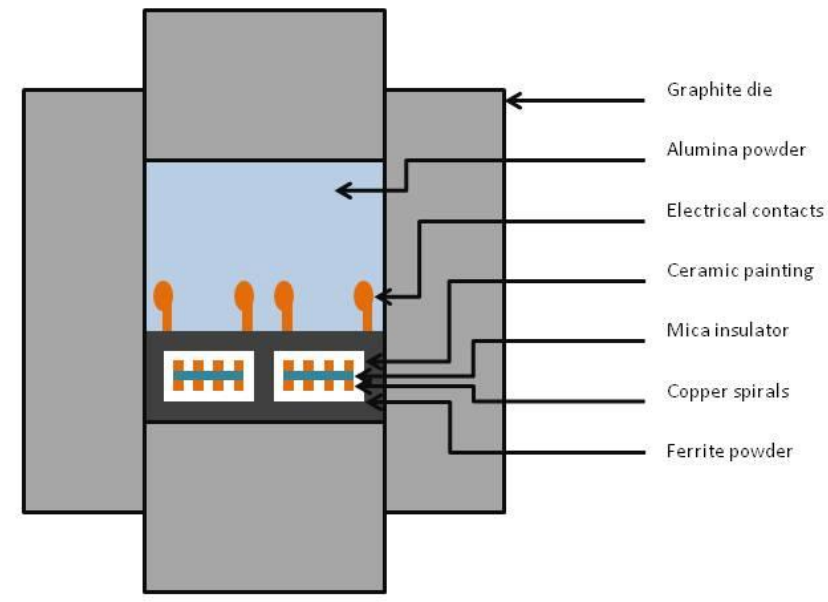

Figure 6. Die before sintering

Subsequently, PECS/SPS sintering was performed in the following way. The temperature increased from $20{ }^{\circ} \mathrm{C}$ up to $800{ }^{\circ} \mathrm{C}$ in $5 \mathrm{~min}$, was kept constant for $10 \mathrm{~min}$, and then decreased down to $20^{\circ} \mathrm{C}$ in $5 \mathrm{~min}$. A uniaxial pressure of 50 $\mathrm{MPa}$ is maintained throughout the operation. As in any PECS/SPS sintering, this pressure is applied to the outer ends of the pistons. The pressure inside the mold is therefore neither known nor homogeneous, as is illustrated in these books [18][19]. These sintering parameters are related to the nature of the ferrite to be sintered, and have already been the subject of previous studies [20]. Finally, the alumina powder is removed and the electrical contacts can be welded to wires in order to perform the measurements. This last step is illustrated in Figure 7.

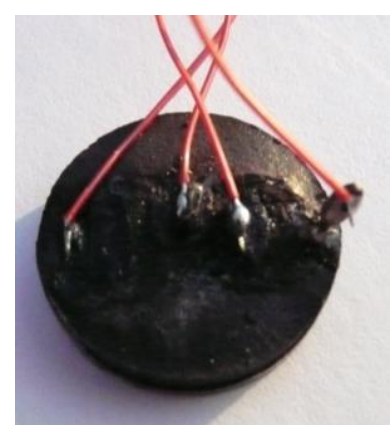

Figure 7. Coupler (ICT). Diameter $20 \mathrm{~mm}$. Thickness $3 \mathrm{~mm}$

The coupler has been characterized as a transformer and the transformation ratio as a function of the frequency has been measured to provide the useful frequency band. Experimental measurements are performed with the HP4194A impedance analyzer in gain-phase mode. The results are shown in Figure 8. 


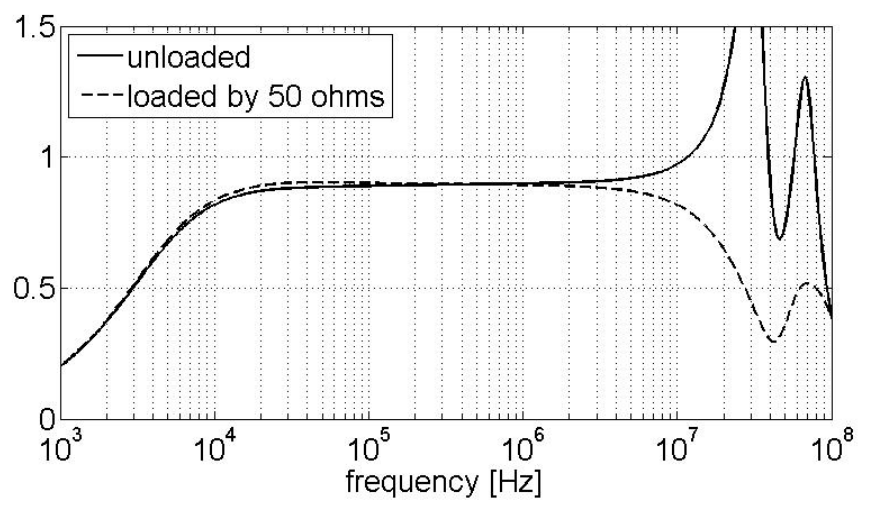

Figure 8. Transformation ratio of an ICT.

The transformation ratio remains almost constant in the range from $10 \mathrm{kHz}$ to $10 \mathrm{MHz}$ and takes a value around 0.9 . Resonance is observed when the transformer is unloaded due to the parasitic capacitance. This phenomenon is damped when the transformer is loaded with $50 \Omega$. When the frequency is set to $2 \mathrm{MHz}$, this ratio is 0.90 and 0.89 for the unloaded and loaded transformer, respectively. The frequency dependence of the self and mutual inductances are shown in Figure 9.
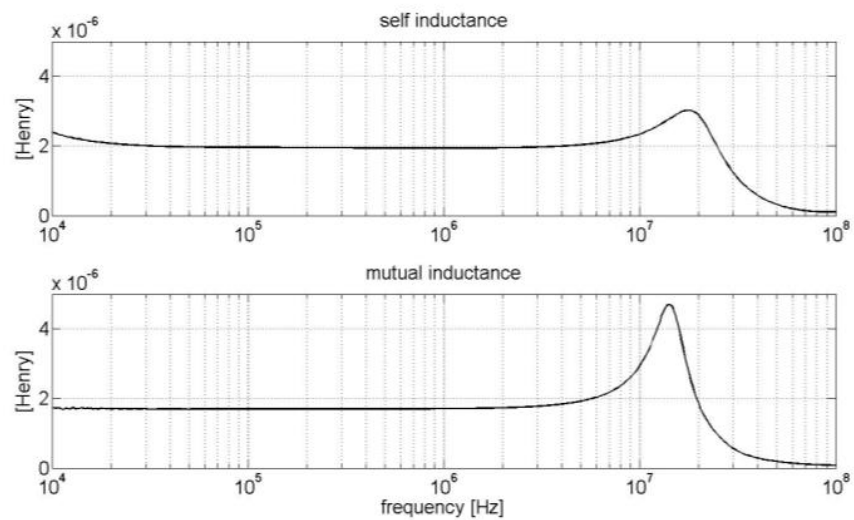

Figure 9. Self and mutual inductances of an ICT.

The low values of these inductances are explained by the small dimensions of the couplers and the number of turns of the two windings which is only 4. However, these inductance values are enough for the application since the switching frequency is $2 \mathrm{MHz}$ and the voltage is low $(<100 \mathrm{~V})$.

Finally, the insulation resistance between the windings were measured. It was observed that this resistance varied from $150 \Omega$ to $2800 \Omega$ for different samples. It should be noted that such dispersion is not found on the inductance values neither on the transformation ratio values. The low insulation resistance values were unexpected and may degrade the operation of the power supply. To identify the cause of this issue, X-ray computed tomography (CT) scan was used to visualize the inside of the components.

A cross-section view of the coupler is shown in Figure 10. One can observe that the copper spirals were not deformed during the sintering and the space between them shows that the insulator fulfilled the galvanic insulation requirements. Although the ceramic painting does keep the windings and the ferrite out of touch, the thickness of this layer is not uniform and may be too thin at some points. Electrical current can then pass through the ferrite core, which would explain the low insulation resistance. The dispersion of the resistance values can be explained by the fact that the application of the paint is done for the moment by hand, preventing us to obtain a good reproducibility from one sample to another.

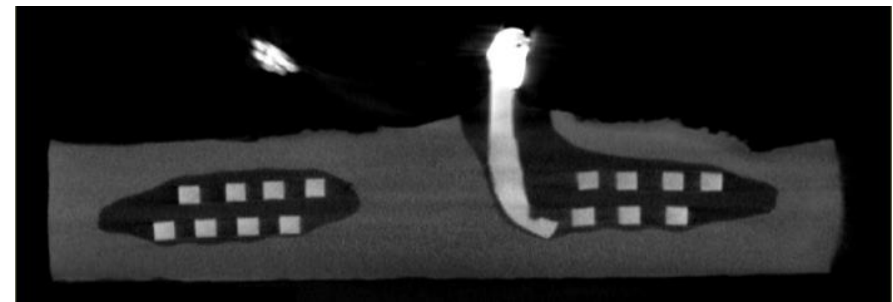

Figure 10. Section view of an ICT by CT scan

The analysis of Figure 10 offers also an insight about the shape of the magnetic circuit. One can observe that the upper surface is not flat. In fact, the alumina powder displaces the ferrite powder during the application of the uniaxial pressure, making the thickness of the magnetic circuit not uniform. This may favour local magnetic saturation of the material leading to an increase in magnetic losses. To tackle this issue, the presintering step was modified as described below.

\subsection{Second ICT production method}

For the second strategy, the thickness of the layer of paint that isolates the windings and the ferrite was increased, and two alumina washers were placed above and below the coupler, see Figure 11. These washers give rise to a flat upper surface and also limit the contact between the graphite die and the ferrite during sintering. Indeed, the carbon is partly responsible for the reduction of ferrite and therefore for its low resistivity.

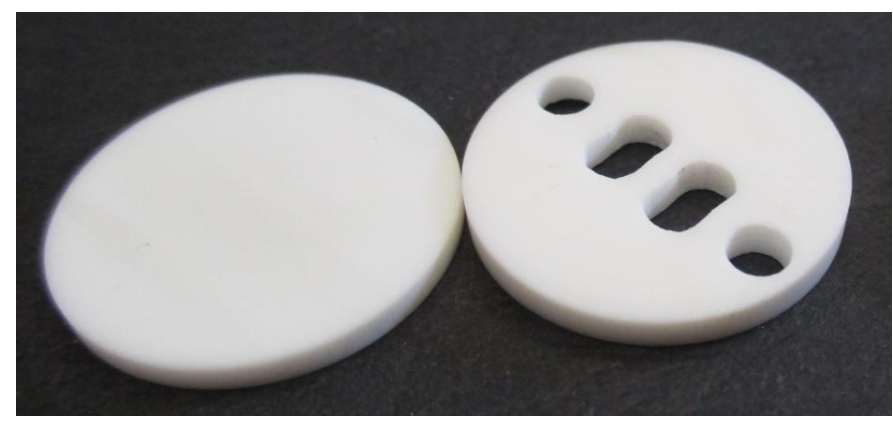

Figure 11. Alumina washer. Diameter $20 \mathrm{~mm}$.

Four holes were drilled in the upper washer for passing the copper contacts and the bottom alumina washer was placed in the graphite die. Then the same procedure described above (first strategy) was followed by inserting 2 grams of powder, the coil set, and 2 more grams of powder. Next, the second alumina washer was placed and the contacts were buried with alumina powder. A section of the filled die before sintering is shown in Figure 12.

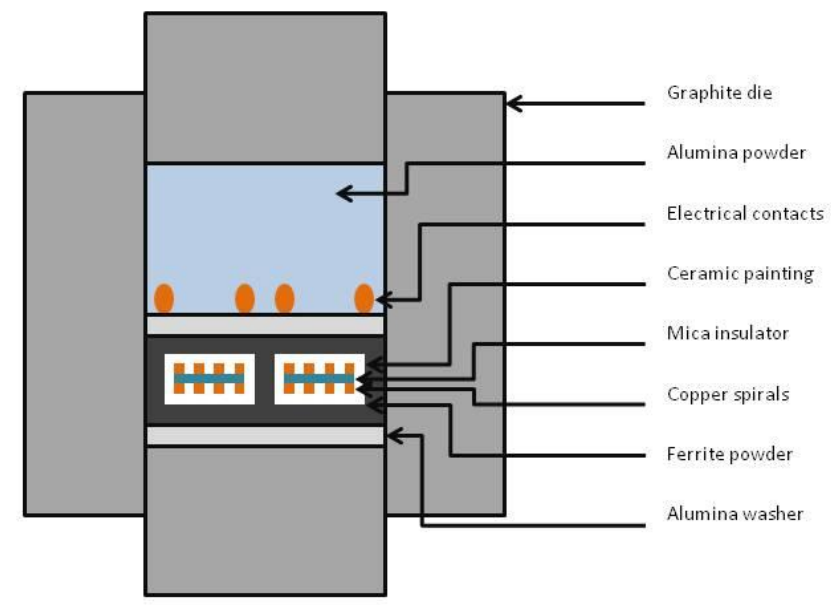

Figure 12. Die before sintering. 
The sintering was carried out at $800{ }^{\circ} \mathrm{C}$ for 10 minutes under a uniaxial pressure of $50 \mathrm{MPa}$. During the heat treatment, the ferrite powder co-sintered with the alumina washers, and it is no longer possible to separate them, as shown in Figure 13. Subsequently, the volume of the washers can be reduced by polishing.

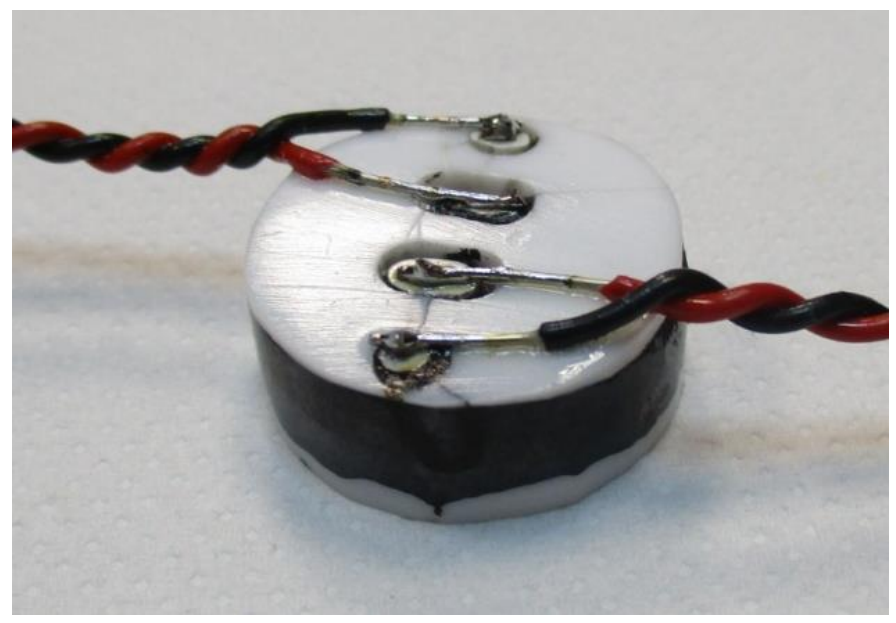

Figure 13. Coupler (ICT). Diameter $20 \mathrm{~mm}$, ferrite thickness $3 \mathrm{~mm}$.

A set of four couplers has been manufactured. The same measurements as above are carried out, starting with the transformation ratio, then the self and mutual inductances and the insulation resistance. Figure 14 presents the transformation ratio with respect to the frequency and Figure 15 shows the self and mutual inductances for one of the couplers.

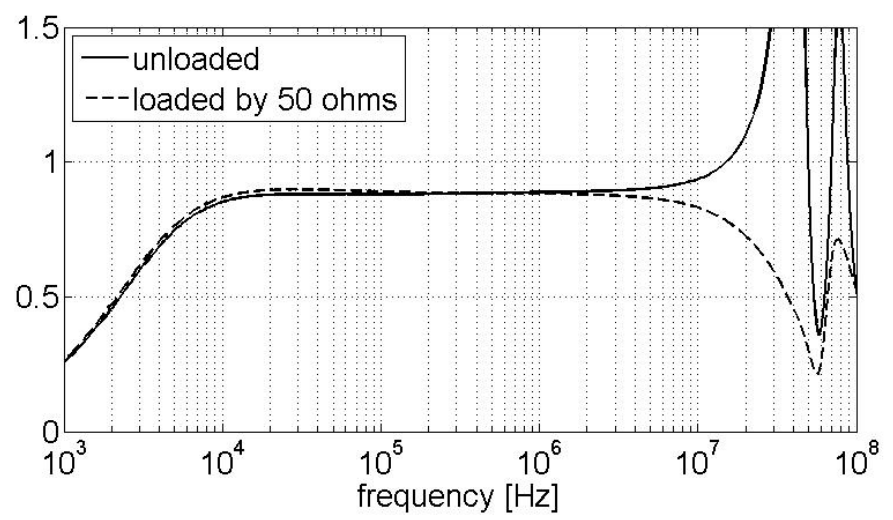

Figure 14. Transformation ratio of an ICT.

One can observe that the useful bandwidth remains between $10 \mathrm{kHz}$ and $10 \mathrm{MHz}$ and the transformation ratio is around 0.9 . At $2 \mathrm{MHz}$, this ratio is 0.891 and 0.879 for the unloaded and loaded transformer, respectively.
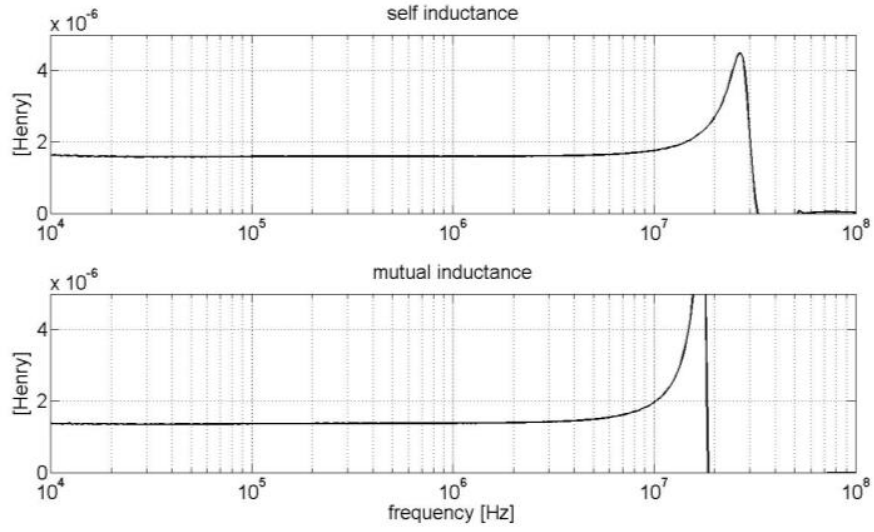

Figure 15. Self and mutual inductances of an ICT.

Regarding the inductances, one can observe that they remain constant for the whole bandwidth and that they are slightly lower than in the first samples represented in Figure 9.

Direct measurement at the ohmmeter indicates that the DC insulation resistance varies between $10.6 \mathrm{k} \Omega$ and $1.20 \mathrm{M} \Omega$. The insulation resistance has been significantly increased by thickening the layer of paint. However, the dispersion in the values remains due to manual application of the paint. Once again, computed tomography confirms these deductions as illustrated in Figure 16.

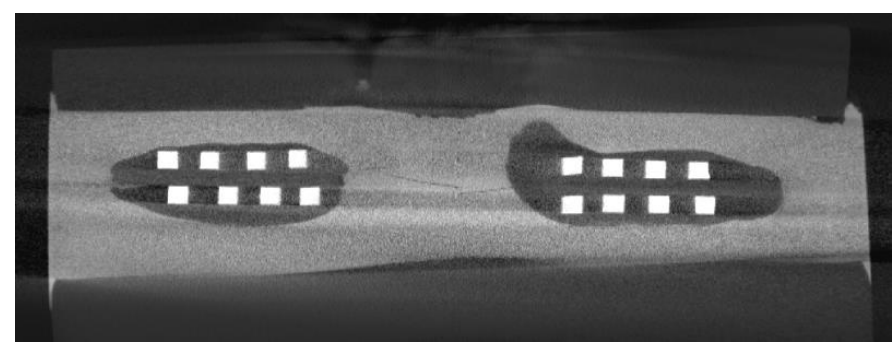

Figure 16. Section view of an ICT by CT scan.

Comparing Figures 16 and 10, one can observe that the insulation coating is thicker, and that the upper surface of the ferrite is flatter thanks to alumina washer. However, since the ferrite co-sintered with the washers, residual stresses appear during the decrease of the temperature. This causes horizontal cracks in the magnetic material that can be observed on the central leg in Figure 16. These cracks create a gap that explains the decrease of the inductances with respect to the previous coupler. They may, however, also contribute to the better insulation resistance. The following table shows the characteristics of the four couplers and illustrates the disparity in electrical quantities.

Table 1. Electrical characterizations of the couplers (ICTs).

\begin{tabular}{|c|c|c|c|}
\hline Coupler & $\begin{array}{c}\text { Insulation } \\
\text { resistance }(\mathrm{k} \Omega)\end{array}$ & $\begin{array}{c}\text { Self inductance at } \\
2 \mathrm{MHz}(\mu \mathrm{H})\end{array}$ & $\begin{array}{c}\text { Mutual inductance at } \\
2 \mathrm{MHz}(\mu \mathrm{H})\end{array}$ \\
\hline$\# 1$ & 31,8 & 1,60 & 1,39 \\
\hline$\# 2$ & 1200 & 1,37 & 1,21 \\
\hline$\# 3$ & 10,6 & 1,85 & 1,71 \\
\hline$\# 4$ & 138 & 1,64 & 1,48 \\
\hline
\end{tabular}


The dispersion on the resistance values is due to the fact that the paint is applied manually, so the thickness is uneven. The dispersion on the inductance values is due to the fact that the copper spirals can move in the graphite die during the application of the uniaxial pressure, and as a result the reluctance varies from one sample to another. Despite this, we decided to keep the couplers manufactured with the alumina washers in order to produce the power supply, since it is preferable to have a good insulation resistance even at the expense of a decrease in the values of the inductances.

\section{ELECTRIC SIMULATIONS}

The size of the ICTs is constrained by the size of the graphite die. In order to estimate if these ICTs could be used in a VRM converter and to determine the operating point, a simulation implemented in Matlab Simulink was done. An ideal behaviour was simulated for each component:

The DC power supply is represented by an ideal DC voltage source of $24 \mathrm{~V}$.

The semiconductors are replaced by ideal switching cells: the voltage output and the current input of the switching cell are respectively equal to the product of the switching function (ideal square function with a duty cycle equals to 0.5 ) by the DC input voltage and the output currents.

The ICTs are represented by their self inductances in series with a constant resistance of the windings and by their mutual inductances (data extracted from measurements are in Table 1).

The output of the DC-DC converter consists in an ideal capacitor $(1 \mu \mathrm{F})$ associated in derivation to resistor $(2 \Omega)$.

Results of simulation are represented in Figure 17. The nomenclature of the electrical quantities corresponds to that of Figure 1: $i_{1}$ is the current in one of the ICTs, $i_{S}$ is the total output current before the capacitor and the load, $V_{1}$ is the output voltage of a switching cell, and $\mathrm{V}_{\mathrm{S}}$ is the output voltage.

This simulation was done for a switching frequency of 2 MHz. This value is compatible with the ICTs bandwidth and compatible with the $\mathrm{GaN}$ semiconductors. In this configuration, the current ripple in each phase is about $2 \mathrm{~A}$ (with a mean value equals to $6 \mathrm{~A}$ ) and the output current presents a lower ripple and a frequency component at $3 \times 2 \mathrm{MHz}$, as expected. The output current ripple is absorbed by the output capacitor which ensures the stability of the output voltage.

(a)



These results confirm that the designed ICTs present enough self and mutual inductance to be used in a VRM converter, and will be discussed in the next section.
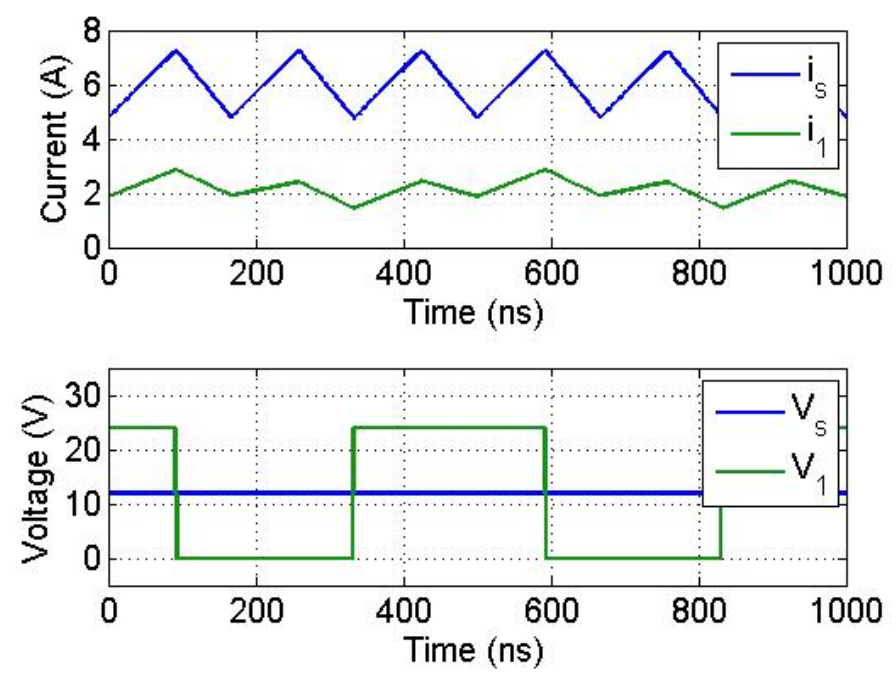

Figure 17. Currents and voltages simulated.

\section{DESCRIPTION OF THE PROTOTYPE}

A picture of the prototype represented in Figure 1 is given in Figure 18 (a). The switching cells are made of $\mathrm{GaN}$ components from Texas Instruments (LMG5200, 80V, 10A). The advantage of this component is that the gate drivers (bootstrap) are directly integrated in the same package, which facilitates the implementation and limits stray elements between the gate and the driver. Moreover, management of dead time is simplified by using requirements of the application note of the datasheet. A picture of a half bridge is presented in Figure 18 (b), showing the GaN components and their integrated driver (LMG5200), the dead time adjustment circuit and the filtering circuit of the power supply of the driver. The decoupling capacitors of the DC bus are SMD components mounted crosswise in order to minimize the inductance of the switching cell loop as much as possible. The DC bus voltage is realized using top $\left(+V_{\mathrm{DC}}\right)$ and bottom $\left(-V_{\mathrm{DC}}\right)$ of the $\mathrm{PCB}$.

Figure 18. (a) View of the prototype. (b) Zoom on a switching cell with driver (LMG5200).

(b)

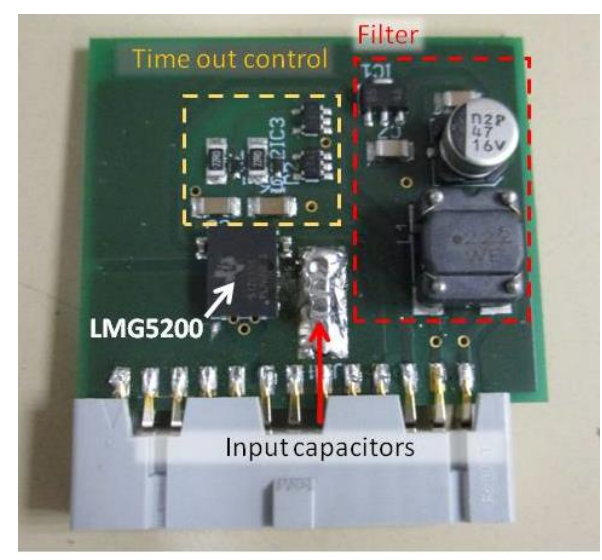


The same electrical quantities as the ones of the simulation are measured and represented in Figure 19 under the same conditions: $V_{\mathrm{DC}}=24 \mathrm{~V}, \alpha=0.5, f_{\mathrm{S}}=2 \mathrm{MHz}$. The waveforms are very close to the simulated ones. It must be noted that it is difficult to access to the output potential of the switching cell close to transistor and that the measurement is degraded by the parasitic inductances of the probe.
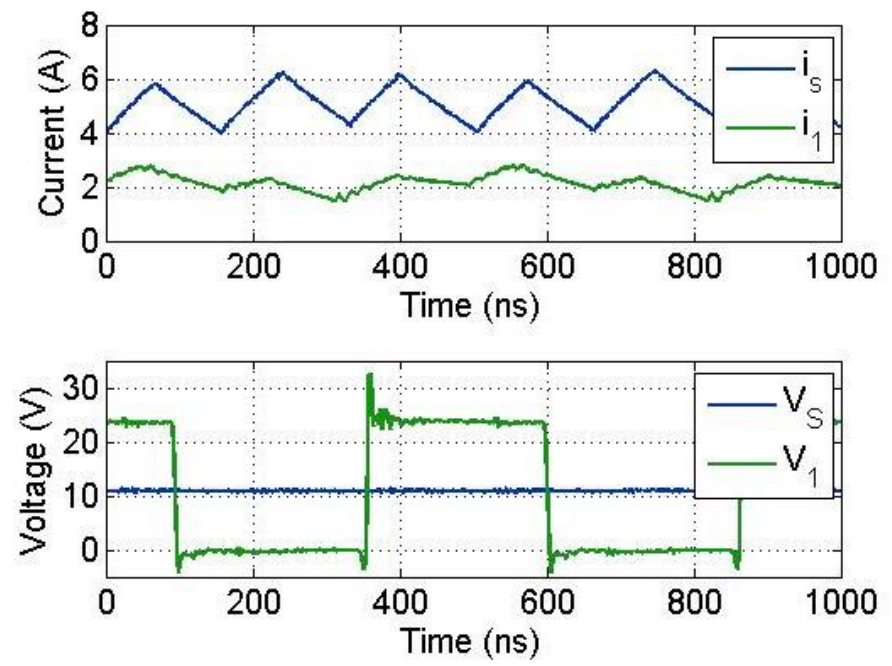

Figure 19. Current and voltage measurements of the VRM.

These waveforms were acquired by probes connecting to an oscilloscope, LeCroy WaveRunner HRO 66Zi (600 MHz, 12 bit, $2 \mathrm{GS} / \mathrm{s})$. The good correlation between the simulation and the experimental results imply that for the switching frequency of $2 \mathrm{MHz}$ :

- the switches can be considered as ideal. Commutation and conduction losses in the switches do not affect the operation of the converter (from the waveform point of view),

- the model of the ICTs implemented in the simulation is complex enough and sufficient to recreate a good behaviour of the ICTs. Copper and magnetic losses do not affect the behaviour: an ICT can be represented by two coupled constant inductances whose mutual inductance is also constant (parasitic capacitance does not affect the behaviour). In the simulation, the resistance of the windings is considered as a constant, which means that the skin effect can be neglected.

(a)

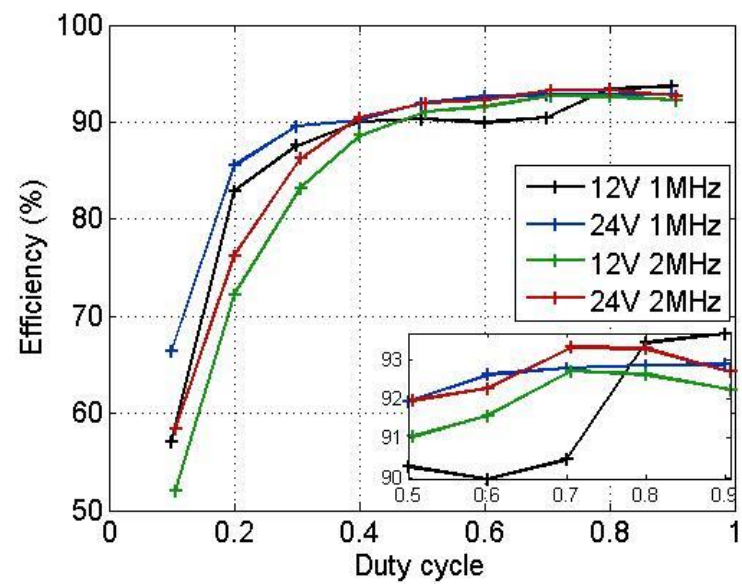

These results allow to validate the choice of the switching frequency and the fact that the ICTs present a good behaviour up to a switching frequency of $2 \mathrm{MHz}$.

Figure 20 shows a synchronous measurement of the output currents of the three switching cells. Because the ICTs are not strictly identical, currents are unbalanced. To solve this problem, current regulation loops must be implemented in future work.

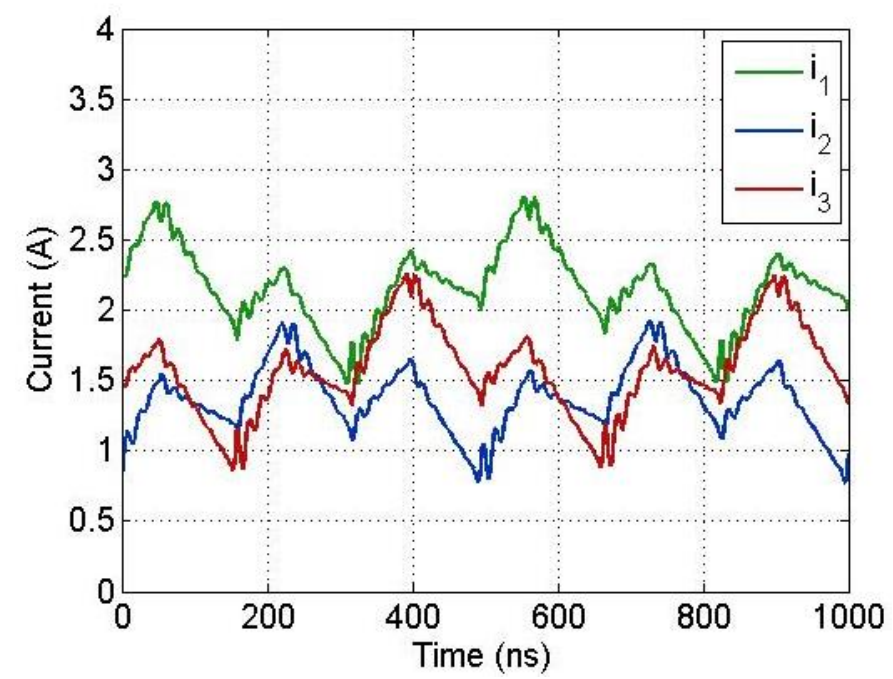

Figure 20. Output currents of the three switching cells.

In order to evaluate the performance of the prototype, an efficiency measurement was realized. The input and output power are calculated by the product of the mean value of the input and output voltages and currents, respectively. These measures were made by Keysight 34465A multimeters.

Figure 21 (a) presents the efficiency as a function of the duty cycle for input voltages of $12 \mathrm{~V}$ and $24 \mathrm{~V}$ and for switching frequencies of 1 and $2 \mathrm{MHz}$. The efficiency reaches a maximum value of $93.7 \%$ for a voltage of $12 \mathrm{~V}$ and a switching frequency of $1 \mathrm{MHz}$. Figure 21 (b) shows the total efficiency as a function of the output power. The maximum power output from the converter reaches $191 \mathrm{~W}$ for a voltage of $20 \mathrm{~V}$ and a current of $9.55 \mathrm{~A}$.

(b)

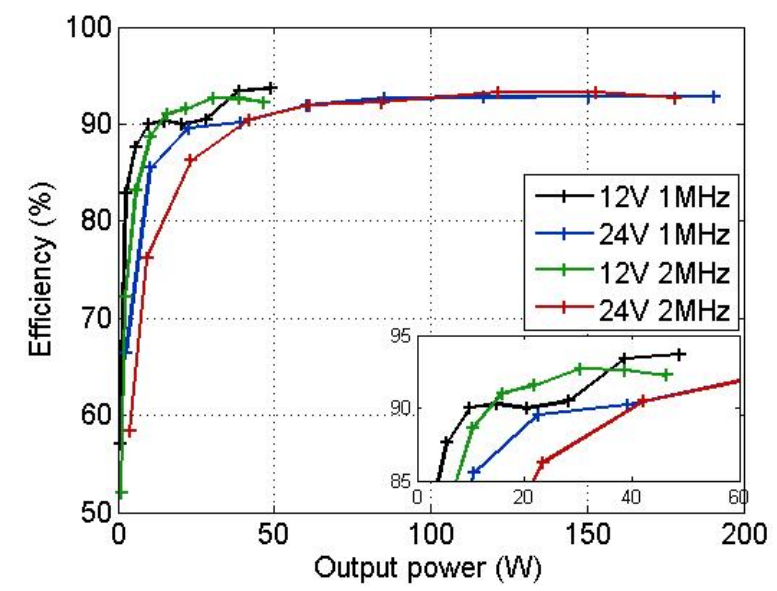

Figure 21. Efficiency of the prototype versus (a) duty cycle and (b) output power. 
In order to estimate the distribution of the losses in the structure, the losses are measured at a fixed duty cycle for several switching frequencies, and represented in Figure 22. The extrapolation allows to estimate the static losses (DC losses + conduction losses) which are equal to $2.33 \mathrm{~W}$ for an output power of $31 \mathrm{~W}$. For this output power, at $2 \mathrm{MHz}$, total losses are equal to $3.1 \mathrm{~W}$. As a consequence, DC losses represent $75 \%$ of the losses. These losses are located in the semiconductors (conduction losses), in the windings of the ICTs, but essentially in the tracks of the prototype. Indeed, wiring is not optimized in order to easily measure the electrical quantities. In a future work, a more integrated prototype will be realized where we hope to obtain a better efficiency (by minimizing losses in copper tracks).

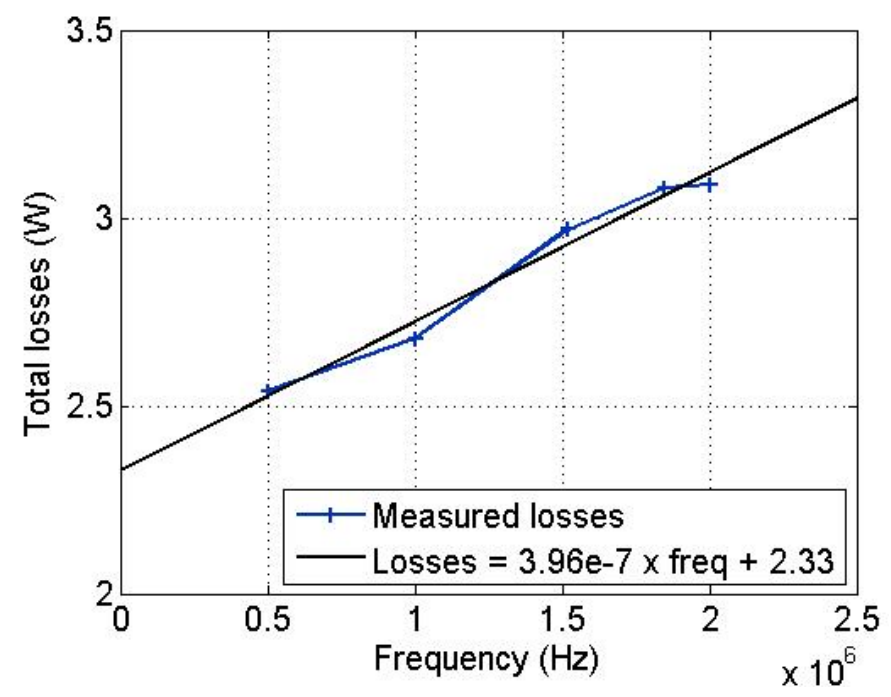

Figure 22. Losses with respect to the frequency.
Finally, power density of the DC-DC converter is estimated. Two volume estimations are considered. The first one takes into account the total space requirement of the components, where each part of the supply is considered to be encapsulated in a rectangular parallelepiped. For example, for cards containing the switching cells, the size corresponds to the product of the width of the card by the length of the card by the height of the largest component. This is intended to give an order of magnitude for a real power supply. In this case power density is equal to $15.2 \mathrm{~kW} / \mathrm{dm}^{3}$. The second volume estimation is limited to the sum of the volumes of the components (with their associated PCB volume) to give an order of magnitude of an ideal power supply, where all space would be occupied. In this second case, power density is equal to $29.8 \mathrm{~kW} / \mathrm{dm}^{3}$.

\section{CONCLUSION}

This paper presents the implementation of an interlaced DC-DC converter coupled by monolithic ICTs. The methods of sintering the ICTs as well as the use of the GaN components have been thoroughly discussed. Results show that the design of the ICTs are functional and they present enough bandwidth to be used in a converter operating at up to $2 \mathrm{MHz}$. The nonoptimized designed converter presents a high efficiency (up to $93.7 \%)$ and a high power density $\left(15 \mathrm{~kW} / \mathrm{dm}^{3}\right)$ and enables the validation of the functional aspects of the structure.

In the future, the design of the ICTs will be optimized and a more precise characterisation of the ICTs will be done (magnetic and copper losses, maximum current until saturation, admissible current in windings, temperature elevation, etc.). Future work will also focus on current regulation loops and on obtaining a more compact design in which copper losses in tracks will be decreased. This improvement will allow to increase the efficiency and the power density of the converter.

Table 2. Power densities

\begin{tabular}{|c|c|c|c|c|c|}
\cline { 2 - 6 } \multicolumn{1}{c|}{} & $\begin{array}{c}\text { Filter and } \\
\text { control }\end{array}$ & $\begin{array}{c}\text { Power } \\
\text { components }\end{array}$ & ICTs & $\begin{array}{c}\text { Output } \\
\text { capacitor }\end{array}$ & $\begin{array}{c}\text { Power density } \\
\left(\mathrm{kW} / \mathrm{dm}^{3}\right)\end{array}$ \\
\hline $\begin{array}{c}\text { Real volume } \\
(\mathrm{cm} 3)\end{array}$ & 2,6 & 4,5 & 4,8 & 0,7 & 15,2 \\
\hline $\begin{array}{c}\text { Ideal volume } \\
(\mathrm{cm} 3)\end{array}$ & 1,2 & 1,5 & 3 & 0,7 & 29,8 \\
\hline
\end{tabular}

\section{ACKNOWLEDGEMENTS}

This work was funded by the EADS Foundation. This work has also been financially supported by the French "Agence Nationale de la Recherche," through the "Investissements d'avenir" program (ANR-10- EQPX-37 MATMECA Grant). We thank Benjamin Smaniotto for his help with the CT scan pictures.

\section{REFERENCES}

[1] Forest, F., Labouré, E., Meynard, T. A., \& Smet, V. (2009). Design and comparison of inductors and intercell transformers for filtering of PWM inverter output. IEEE Transactions on Power Electronics, 24(3), 812821.

[2] Park, I. G., \& Kim, S. I. (1997, June). Modeling and analysis of multiinterphase transformers for connecting power converters in parallel. In
Power Electronics Specialists Conference, 1997. PESC'97 Record., 28th Annual IEEE (Vol. 2, pp. 1164-1170). IEEE.

[3] Xu, Peng., Wei, J., \& Lee, F. C. (2003). Multiphase coupled-buck converter-a novel high efficient $12 \mathrm{~V}$ voltage regulator module. IEEE Transactions on Power Electronics, 18(1), 74-82.

[4] Forest, F., Meynard, T., Laboure, E., Costan, V., Sarraute, E., Cuniere, A., \& Martire, T. (2001). Optimization of the Supply Voltage System in Interleaved Converters Using Intercell Transformers. IEEE Transactions on Power Electronics, 22(3), 934-942.

[5] Munir, Z. A., Anselmi-Tamburini, U., \& Ohyanagi, M. (2006). The effect of electric field and pressure on the synthesis and consolidation of materials: a review of the spark plasma sintering method. Journal of Materials Science, 41(3), 763-777.

[6] Munir, Z. A., Quach, D. V., \& Ohyanagi, M. (2011). Electric current activation of sintering: a review of the pulsed electric current sintering process. Journal of the American Ceramic Society, 94(1), 1-19.

[7] Orrù, R., Licheri, R., Locci, A. M., Cincotti, A., \& Cao, G. (2009). Consolidation/synthesis of materials by electric current activated/assisted sintering. Materials Science and Engineering: R: Reports, 63(4), 127-287. 
[8] Yamamoto, S., Horie, S., Tanamachi, N., Kurisu, H., \& Matsuura, M. (2001). Fabrication of high-permeability ferrite by spark-plasmasintering method. Journal of magnetism and magnetic materials, 235(1), 218-222.

[9] Sun, J., Li, J., Sun, G., \& Qu, W. (2002). Synthesis of dense NiZn ferrites by spark plasma sintering. Ceramics international, 28(8), 855858.

[10] Mazaleyrat, F., Zehani, K., Loyau, V., \& Labouré, E., (2015). Method for producing a monolithic electromagnetic component and associated monolithic magnetic component. Patent WO2015028389 A1.

[11] Mercier, A., Zehani, K., Chaplier, G., Pasko, A., Loyau, V., \& Mazaleyrat, F. (2016). Spark Plasma Sintering Co-Sintered Monolithic Transformers for Power Electronics. IEEE Transactions on Magnetics, 52(5), 8400404.

[12] [12] Caltun, O. F., Spinu, L., Stancu, A., Thung, L. D., \& Zhou, W. (2002). Study of the microstructure and of the permeability spectra of $\mathrm{Ni}-\mathrm{Zn}-\mathrm{Cu}$ ferrites. Journal of Magnetism and Magnetic Materials, 242, 160-162.

[13] [13] Nakamura, T. (1997). Low-temperature sintering of NiZnCu ferrite and its permeability spectra. Journal of Magnetism and Magnetic Materials, 168(3), 285-291.

[14] [14] Hu, J., \& Yan, M. (2005). Science letters: Preparation of highpermeability NiCuZn ferrite. Journal of Zhejiang University. Science. B, $6(6), 580$.

[15] [15] Hsu, J. Y., Ko, W. S., \& Chen, C. J. (1995). The effect of V2O5 on the sintering of NiCuZn ferrite. IEEE Transactions on Magnetics, 31(6), 3994-3996.

[16] [16] Lebourgeois, R., Duguey, S., Ganne, J. P., \& Heintz, J. M. (2007). Influence of $\mathrm{V} 2 \mathrm{O} 5$ on the magnetic properties of nickel-zinc-copper ferrites. Journal of Magnetism and Magnetic Materials, 312(2), 328-330.

[17] [17] Valenzuela, R., Gaudisson, T., \& Ammar, S. (2016). Severe reduction of $\mathrm{Ni}-\mathrm{Zn}$ ferrites during consolidation by Spark Plasma Sintering (SPS). Journal of Magnetism and Magnetic Materials, 400, 311-314.

[18] [18] McColm, N. J., \& Clark, N. J. (1988). Forming, shaping and working of high-performance ceramics. Springer. ISBN: 0216920094.

[19] [19] Valenzuela, R. (2005). Magnetic ceramics (Vol. 4). Cambridge University Press. ISBN: 0521018439.

[20] [20] Zehani, K., Mazaleyrat, F., Loyau, V., \& Labouré, E. (2011). Effect of temperature and time on properties of spark plasma sintered NiCuZn: Co ferrite. Journal of Applied Physics, 109(7), 07A504. 